\title{
Impact of Supply Chain Management Practices on Organizational Performance: A Case Study of Haco Industries Limited (Kenya).
}

\author{
Makena Naomi Mutuerandu, Directed by Dr. Mike Iravo \\ Department of Entrepreneurship and Procurement in the school of Human Resource Development, Jomo \\ Kenyatta University of Agriculture and Technology, Kenya
}

\begin{abstract}
Supply chain management (SCM) is one of the most important tools that companies use to develop their performances. The basic objectives of this research were (1) to assess the level of implementation of SCM practices in Haco Industries Ltd, and (2) to study the relationship between SCM Practices and organizational performance in the same industries. To study the relationship between supply chain management practices and organizational performance, four key dimensions of SCM practices (strategic supplier partnership, customer relationship, information sharing and training practices) were used as independent variables, while market/business and operational performance variables were used to measure the organizational performance. A sample of 40 employees was taken conveniently. Aquestionnaire was used as a research tool for the collection of data. Baseline data was gotten from some key informants and also from secondary data.Collected data were analyzed through SPSS XVIII by running frequencies, mean score.

Main findings of the study revealed that there is a high level of practical implementation of SCM practices in Haco Industries ltd and that they all had a positive effect on organization's performance that is they improved the organization's performance in terms of lowering its operational costs, reduction of lead time, high customer service levels, product quality, fast response to changes in the market and expanding its market share and sales.A combination of all the four practices studied had a stronger effect on organization performance other than the effect of one which further shows the need to embrace a good combination of SCM practices.
\end{abstract}

Keywords: Organizational performance, Supply chain management, Supply chain management practices

\section{Introduction}

Due to the number of rival companies expanding both locally and globally, companies not only have to reestablish themselves to produce higher-quality products and services, decrease waste and are able to respond to the market but also to handle their supply chain management efficiently. Organizations are facing different kinds of challenges in their effort of competing in today's dynamic global markets. To remain competitive, organizations must recognize the importance of supply chain practices that improve not only their own organizational performance, but also coordinate with their supply chain partners to improve their joint performance. Yet, despite the significant advances in research and practices, many organizations continue to struggle to understand the complex issues associated with the coordinated planning and supply activities amongst the members of their supply networks (Lori et al., 2011).

Supply chain management is, "a set of three or more entities (organizational or individuals) directly involved in the upstream and downstream flow of products, services, finances, and/or information from source to customer" (Mentzeret al., 2001). SCM practices have been defined as the set of activities undertaken in an organization to promote effective management of its supply chain (Li et al., 2006). The best supply chain practices are the initiatives that influence the whole supply chain, its parts or key processes (Cuthbertson and Piotrowicz, 2008). These practices are influenced by contextual factors such as type of industry, firm size, its position in the supply chain, type and length of supply chain (Li et al., 2006).

A clear definition of firm performance is required in clarifying the multidimensional relationship between SCM practices and firm performance. The notion of firm performance has many aspects, and each aspect has been operationalized in various ways in previous supply chain management studies. For example, Flynn et al. (2010) reveal that operational performance and business performance are the two most utilized measures of firm performance. Following these studies, this research considered operational performance and business performance as two key aspects of firm performance.

The recent business environment is growing to be more challenging, and so, companies have to increase their business operations to stay competitive. According to this idea, one of the most important factors for improving business operations is implementing of supply chain management practices that will translate into improved organizational performance. 
Although SCM is currently no longer a new strategy, there are still some serious practical problems that have yet to be addressed. Like lack of basic knowledge of SCM amongst the business practitioners and even though some of the practitioners have realized the importance of SCM, they lack an understanding of what constitutes a comprehensive set of SCM practices.

It is only by embracing supply chain management practices that companies such as Haco Industries Ltd will be recognized by their customers and industry as highly effective professionals who contribute towards the most cost effective business solutions. Since there are hardly any studies related to the know-how of SCM practices as well as their effect on organizational performance in Kenyan manufacturing companies. Therefore, the researcher needed to study commonly advocated SCM practices used in previous researches in other countries Li et al., (2005), Li et al., (2006), Lori et al., (2011) that include strategic supplier partnership, customer relationship, Information sharing and training impact on organizational performance in Kenyan industries .

Haco industries was chosen as the unit of study because it is a multinational organization, the way it fasts and often introduces new products to the market, formation of partnerships and its outstanding performance. The company also has a diversified product portfolio that is normally used by virtually all groups of people.

The findings of the proposed study will have both theoretical and practical implications for the future of supply chain management in Kenya. Theoretically the study is expected to contribute to the advancement of knowledge about the importance of supply chain management practices to organizational performance. The study will be of help in the manufacturing industry in general and open doors to improvement of productivity and performance through the aid of good supply chain management practices. The study was to finally form a base on which others can develop theirs.

\subsection{CONCEPTUAL FRAMEWORK Independent Variables}

\section{Dependent Variable}

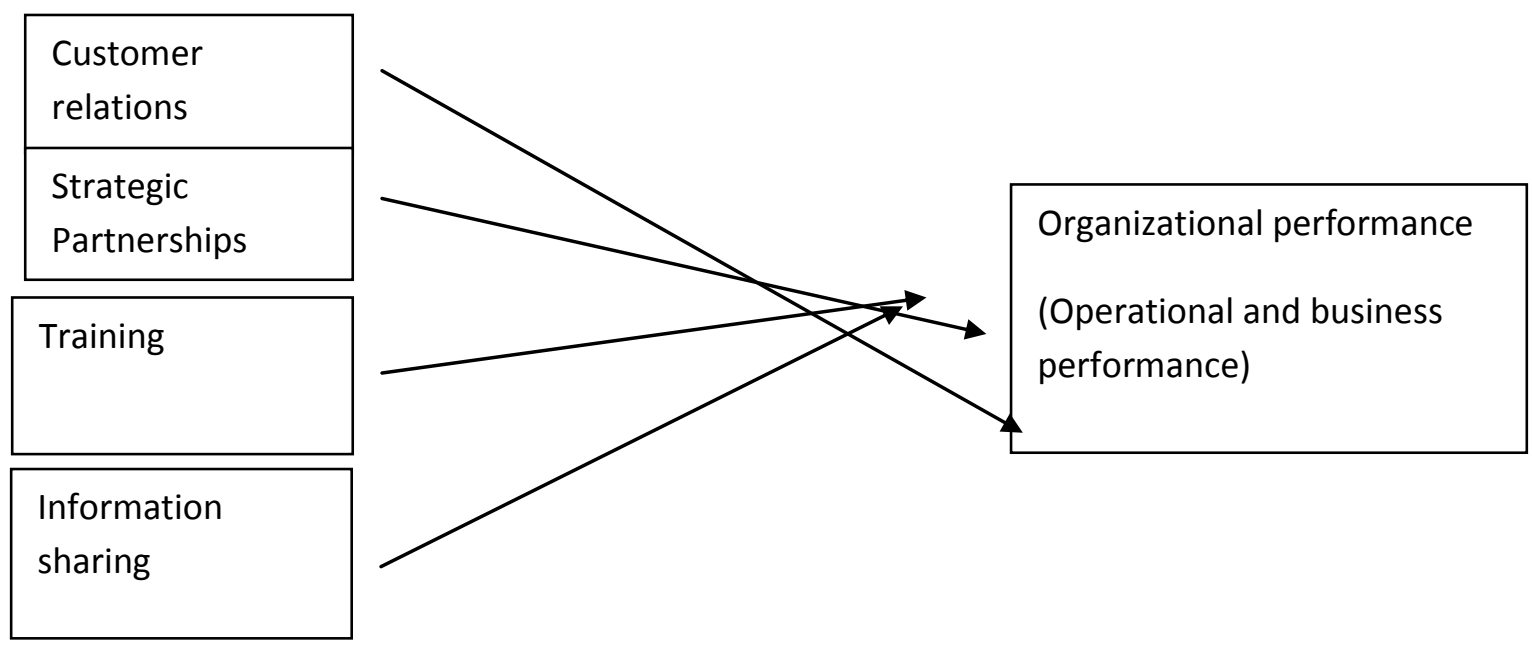

Fig 1.1. Own source

\subsection{REEARCH DESIGN}

\section{Research Methodology}

The impact evaluation study adopted non-experimental design which was a single group post-test only, which was a case study of a single unit of study (Haco industries limited).

\subsection{Instruments and their development}

In this study, a questionnaire on five points (Likert Scale) was used for the collection of data.theLikert scale that was used in this research is considered as categories, not numerical points ( 1 - not at all, 2 - to a small extent, 3 - to a moderate extent, 4 - to a great extent 5 - not applicable). To check for the relationship, values rated from 1 and 2 were considered to have weak effect while values rated 3 and 4 were considered to have a strong effect. Collected data was analyzed through percentage and mean score. Responses of 31 out Of 40 respondents were interpreted and presented in percentage, mean and standard deviation. 


\section{Findings}

Of the 40 questionnaires given to respondents, 31 questionnaires were valid and the responses used for data analysis. This was a response rate of $77.5 \%$.

It was observed that there was no significant difference between gender, section, designation, academic qualification, duration worked in the organization and the view that the commonly advocated SCM practices which includes information sharing, customer relations, strategic partnerships and training improves the organization's performance in terms of its operational and business parameters. This means that regardless of the variables used there is a positive effect of the SCM practices to organizational performance.

From the reports of key informants and secondary data to provide a baseline data, the baseline information indicates that before the implementation of some of the supply management practices especially the strategic partnerships and customer relationship management then the performance of the organization was not as well performing as now in terms of the operational costs, sales and market growth. Therefore the researcher can conclude that there is a positive impact of supply chain management practices to organization performance.

\section{Conclusion}

In conclusion as the research sought to study the effect of supply chain management practices on the organization performance, it was observed that all the supply chain management practices studied had a positive effect on the organization's performance. To improve organization performance the supply chain management focuses on operational time, cost, response, customer service and profitability or margins.

However, it was noted that some of the respondents were not well versed with some of the practices like CRM and hence had missing values. It was noted that some respondents disagreed with implementation of training and this is a very crucial practice as it will improve the individual's performance and morale which will translate into improved organization performance.

From the study we can conclude that the organization performance of Haco industries has improved with the implementation of the said practices as compared to before implementation.

For an organization to achieve a competitive advantage in the global environment, then it has to embrace supply chain practices as its culture. For instance training of employees should be core and this would not be possible without communication within the organization.

Based on research findings, the researcher recommended that managers should take a serious attention on the relationship among Supply chain management practices, and performance improvement in the Kenyan Industry, and should have the correct mix of practices that would lead to improved performance as the combined effect is greater than for one practice.

\section{References}

[1] Lori S. Cook \& Daniel R. Heiser, The moderating effect of supply chain role on the relationship between supply chain practices and performance,InternationalJournal of Physical Distribution \& Logistics Management,41(2),2011, 104-134.

[2] Mentzer, J.T., Flint, D.J., and Hult, G.T.M., Logistics Service Quality as a Segment customized Process, Journal of Marketing, 65(4), 2001, 82-104.

[3] $\mathrm{Li}$, S., et al, The impact of supply chain management practices on competitive advantage and organizational performance, Omega, Vol. 32,2006, 107-24.

[4] Flynn, B.B. et al ,The impact of supply chain integration on performance: a contingency and configuration approach, Journal of Operations Management, Vol. 28, 2010.

[5] Li, S. et al, Development and validation of a measurement for studying supply chain management practices, Journal of Operations Management, Vol. 23(6), 2005, 618-41. 